\title{
A EFICÁCIA NO SERVIÇO DA JUSTIÇA ${ }^{1}$
}

\author{
Christophe Jamin ${ }^{2}$
}

Resumo: Uma reflexão sobre os colóquios 'a eficácia no serviço de justiça', organizados pela Gazeta do Palácio, que aborda quatro aspectos: (1) de racionalizar a organização da instituição, (2) de melhorar a comunicação entre os atores, (3) de formalizar um pouco mais as petições, e (4) de revolucionar a audiência.

Palavras-chave: Eficácia. Justiça. Organização. Centralização. Coordenação. Comunicação. Petições, audiência, novas tecnologias.

\section{INTRODUÇÃO}

Acabamos de encerrar um trabalho, marcado por ricos e fortes debates, que frequentemente se tornavam apaixonados. Esperando não fatigar os leitores, gostaria de introduzir brevemente a síntese em torno das suas linhas principais, e começar a refletir sobre o título de nossas discussões sobre "eficácia no serviço da justiça”.

A escolha do título é muito significativa para o espírito do novo século que marca o momento atual. Nós não hesitamos em associar as palavras "eficácia" e "justiça", e pode-se até dizer

1 Dedicado à memória de Jean-Maxime David (1917-2007), presidente honorário de câmara no Tribunal de Apelação de Versalhes. O presente texto é a versão escrita do resumo do relatório apresentado em 22 de março de 2007 no Palácio de Justiça, preservado o estilo oral. Tradução para o português de Cláudio Eduardo Regis de Figueiredo e Silva, publicado originalmente na Gazette du Palais, sob o título 'L'efficacité au service de la justice', Paris: Placard, GP 128167.

2 Doutor em Direito pela Universidade de Paris I - Panthéon-Sorbonne (1990), catedrático em Direito Privado e Ciências Criminais (1993), e Diretor da École de Droit de Sciences Po (IEP) - Paris. 
que já estamos acostumados com tal associação, mesmo que esta não pareça óbvia.

No início da década de 1980, haveria uma forte oposição à escolha deste tema. Na época o debate tratava acerca de politizar a justiça. Hoje, essa politização já não está mais em questão; não se trata de politizar a justiça, mas de modernizá-la. No espaço público, o judiciário não parece estar sendo avaliado em termos de legitimidade política, mas legitimidade técnica.

O caso Outreau ${ }^{3}$, recente e dramático confirmou: aquilo que alguns sugeriam ser uma notável rede de pedófilos poderia ser o estopim de uma crítica do funcionamento da instituição política judicial. Por não ter assistido até o final a aula de justiça, o judiciário atingiu brutalmente uma das populações mais desfavorecidas do Pas-de-Calais. Criticou-se, sobretudo, um juiz que não foi tecnicamente capaz de gerir o caso, mas que também falhou na parte da humanidade (essa falta de humanidade que nos aparece em termos de experiência profissional, e que deve estar sempre ao lado da técnica). De forma mais ampla, o que se criticou foi uma máquina legal que não funcionou de forma suficientemente... eficaz, na medida em que não produziu o efeito que as partes e o público em geral poderiam esperar, especialmente porque permitiu a prisão de muitos acusados por longo tempo, que em sua maioria foram finalmente absolvidos.

Nos debates sobre políticas de justiça foram feitos questionamentos utilizando técnicas emprestadas, em grande parte, do discurso gerencial. Pode-se dizer que esta é uma reflexão que trata menos sobre os fins (nisso precisamos todos muito bem concordar, mesmo porque estaríamos aumentando demais as nossas ambições [1]), do que os meios (que precisam ser melhorados [2]).

30 'affaire d'Outreau' trata de um processo criminal envolvendo um caso de abuso sexual infantil que tramitou em Saint-Omer (Pais-de-Calais). A maior parte das 18 pessoas denunciadas e presas provisoriamente em 2001 veio a ser absolvida pela Corte de Apelação de Paris, em 01 de dezembro de 2005, num dos mais rumorosos casos de erro judiciário da França, objeto de comissões de inquérito, documentários para a TV, e do longa-metragem 'Présumé Culpable', de 2011. (N. do T.) - http://www.ladocumentationfrancaise.fr/rapports-publics/064000468/index.shtml 
Passados 25 anos, agora as palavras que dominam o discurso sobre a instituição do judiciário são de gestão, modernização, capacidade, eficiência, qualidade, desempenho: uma "abordagem de qualidade", nas palavras usadas por um de nossos palestrantes, celeridade e mesmo uma "empresa judicial" [3]. Todos os relatórios fazem tais referências, desde aquele estabelecido pelo presidente Daussy em 1982 (Justiça atrasada, justiça negada), até aquele preparado sob a administração do presidente Magendie em 2004 (Celeridade e qualidade da justiça. Gestão do tempo do processo); para não mencionar os relatórios anuais da CEPEJ, cujo significativo nome é "Comissão Européia para a Eficácia da Justiça”. Utilizando a mesma expressão, eficácia, nós nos inserimos incontestavelmente nesse debate que já se alonga.

No entanto, ainda que usemos um discurso que tenha menos em conta o direito que a gestão, o debate não pode ser transferido para a recente tendência de alguns da análise econômica do direito.

Para compreender melhor, é preciso lembrar que os termos eficiência e eficácia podem ser ambíguos. No sentido mais comum atribuído a este pelo dicionário Robert ${ }^{4}$, é eficaz "o que produz o efeito desejado". Eficiência implica no relacionamento entre um fim a ser alcançado, e no que é implementado para se atingir este fim. Os meios para atingir o fim estabelecido é que terão que ser encontrados para alcançar a eficácia. Neste sentido, veremos o assunto.

Poderíamos ir mais longe e adicionar ao nosso propósito: encontrar uma maneira que consiga, pelo menor custo, o fim que se estabeleceu, conforme o conceito de eficiência mais conhecido. Ora esta abordagem, que se reporta ao âmbito da análise econômica do direito, não é a nossa e nem sempre é aquela que orienta os vários pesquisadores que tem falado sobre a eficácia da justiça nestes vinte cinco anos.

Outra coisa que não se deve esquecer: assumimos que a justiça é um bem comum, o que tem o efeito no debate acerca

4 Dictionnaires LE ROBERT - SEJER, www.lerobert.com (N. do T.) 
das despesas dentro dos limites que são, em última análise, bastante estreitos. No entanto, a questão dos custos tem emergido como uma marca d'água ao longo de nossas discussões. Isso também se tornou necessário: para discutir formas de desenvolver o trabalho, acabamos sempre por pensar em como seria o meio o menos caro, que é concentrar-se no cálculo raciocínio econômico em termos de custo e benefícios. Lembremo-nos a referência o custo da transferência de prisioneiros para justificar o uso de videoconferência em todas as fases do processo penal. Vamos lembrar também das questões levantadas por um advogado na seção da Ordem dos Advogados de Coutance, com relação ao custo do uso de comunicação eletrônica, especialmente quando eles são obrigados a prestar seus serviços a título de assistência jurídica. Lembremo-nos ainda das observações expressadas pelo Sr. Benichou na tribuna: as grandes somas de dinheiro que o Tribunal vai pagar para permitir a desmaterialização do procedimento vão exigir decisões de orçamento difíceis quando as relações entre custo e benefício ocupam um lugar importante...

Deixemos estas questões de ordem econômica e orçamentária e voltemos para a forma como construímos as nossas discussões. Uma vez que especificados termos do nosso assunto (reflexão que certamente recai mais sobre os meios do que sobre o propósito da justiça) e estabelecido o nosso método (uma reflexão sobre os meios que significa tomar emprestado apenas incidentalmente a análise econômica), precisávamos abordar a substância.

Neste ponto, sempre supusemos implicitamente que as regras processuais e sua aplicação poderiam ser uma fonte de eficácia. Ao fazê-lo, mais uma vez seguimos uma escola de pensamento: quando o presidente Magendie dedica uma grande parte do seu relatório de 2004 sobre "a gestão do tempo durante o processo", pressupõe que acelerar o curso da justiça alterando algumas regras de procedimento é a melhor garantia de sua eficácia, admite implicitamente e reconhece pragmaticamente que os jurisdicionados devem receber uma justiça rápida. 
Nós não quisemos plagia-lo. Não se encontra nada explícito no programa de nossas discussões sobre rapidez, celeridade ou aceleração do tempo no processo, mesmo se nós esbarrarmos com uma barreira (por exemplo, uma estrutura de petições que permitisse ao juiz poupar tempo ao escrever a sua decisão). Preferimos nos concentrar em outros aspectos projetados para tornar a justiça mais eficaz. Depois de ouvir todos os oradores, com muito cuidado durante as nossas discussões, essas questões parecem ser em número de quatro, e todas elas parecem traduzir um pouco o que acontece em todos os lugares, e o problema não é realmente a velocidade, mas mais diretamente a qualidade da justiça.[6]

Eu digo isso de uma forma abrupta e com pleno conhecimento de que esses quatro aspectos se sobrepõem mais ou menos à eficácia que a justiça exige hoje: (1) dinamizar a organização da instituição, (2) melhorar comunicação entre os atores, (3) formalizar as petições ainda um pouco mais e, finalmente, (4) revolucionar a audiência.

Veremos cada um desses aspectos após o outro.

\section{DINAMIZAR A ORGANIZAÇÃO DA INSTITUIÇÃO}

Isto é o que conseguimos aprender em grande parte desde Outreau, que não era apenas uma questão de pessoas, mas também de estruturas. Naquela ocasião, mais uma vez se ouviu falar da famosa solidão do juiz de instrução e, no entanto, ao mesmo tempo também se falou da falta de recursos.

De onde se encontram as três palavras-chave: "pólos de instrução", "formação colegiada" e "cosaisine" 5 , todas constantes

5 "Cosaisine [processo penal] Faculdade, o presidente do Tribunal Superior de nomear um ou mais juízes para serem adjuntos ao juiz de instrução, quando a gravidade ou complexidade do caso exigir. Os pólos da instrução só serão competentes para a instrução sujeita à cosaisine. A medida é de aplicação provisória, enquanto se aguarda a entrada em vigor da instrução colegiada, inicialmente prevista para 01 de janeiro de 2010, mas adiada para 01 de janeiro de 2011 pela Lei n. 2009-526 de 12 de maio de 2009 (art. 136). - C. Pr. Pen., Art. 83-1 e 83-2, red. Lei 2007-291 de 05 de março de 2007." (LEXIQUE, 18a. ed., Dalloz, 2011) A vigência foi novamente adiada para 01 de janeiro de 2014 pela Lei $n^{\circ}$ 2010-1657 de 29 de dezembro 2010. (N. do T.) 
no Ato de 05 de março de 2007. Como alguns estão mencionando (ou se não mencionei acima), faz reconhecer como um 'natimorto' (o texto legal não é de aplicação imediata)... que confirma a ideia de que fui o único a levar a sério este texto legal tentando analisá-lo, mesmo que o meu estimado colega Bouloc não quisesse, o que é verdade, devido a uma experiência infeliz no passado (nem todas as reformas do processo penal, ao que parece, destinam-se a serem utilizadas)!

A primeira constatação do neófito que sou, do que me recordo o tempo todo mesmo sendo um profissional do direito penal: a nova arquitetura legal é bastante complexa. Pólos de instrução, 'cosaisine' e formação colegiada se misturam, e sem saber bem, correspondem uns aos outros. No entanto, parece que duas palavras caracterizam esta arquitetura, se não todos o movimento atual de reforma do sistema de justiça criminal: centralização e coordenação.

A instituição dos pólos de instrução é certamente uma lógica centralizadora, que o promotor Marin defendeu dizendonos (cito de memória) que, se a proximidade foi uma coisa boa, a ilusão de proximidade era algo perigoso. Em si, a palavra "pólo" não é muito informativa: ela agora pertence à linguagem simples da reforma administrativa, ele pode servir diferentes políticas. Tomemos o exemplo dos "pólos" de investigação e ensino superior (o famoso "PRES") para aumentar a "eficácia" do sistema de ensino superior e de pesquisa francês. Neste sentido, o Ministério do Ensino Superior pensa em termos de rede e federação atividades, o que realmente não coincide com a lógica usada pelo Ministério da Justiça. Em matéria judicial, nós já conhecíamos os pólos especializados do Tribunal de Grande Instância de Paris: o financeiro, o de terrorismo e de cuidados de saúde, para concentrar as competências e recursos em apenas um lugar para lutar mais eficazmente contra certos tipos de crimes. Com a nova lei, poderão ser designados em breve (?) novos tipos de pólos em certos Tribunais Superiores, por um futuro decreto (?), poder-se-á por um meio oblíquo - mas talvez não muito discreto 
- alterar o mapa judicial. Os juízes que compõem esses grupos terão jurisdição exclusiva para instruções do crime onde houver 'cosaisine'. Estamos, portanto, numa lógica de centralização, o que pode ter movido o presidente Natali a dizer-nos que essa lógica tende a aumentar o custo da justiça (tributo prestado a uma primeira análise econômica do direito), porque é suscetível de gerar custos adicionais aos advogados que estiverem mais distante do pólo, sacrifício este motivado em razão dos direitos de defesa.

Centralização de um lado, coordenação do outro. As palavras estão em toda parte. Primeiro dizem respeito aos pólos, já que o novo artigo 52-1 afirma que "um ou mais juizes podem ficar encarregados... de coordenar as atividades dos juizes dentro do pólo." Também sobre a colegialidade, o novo artigo 83 afirma que "o presidente do tribunal... designa, para cada informação, um colégio de três juizes, dos quais um magistrado de primeiro grau que serve como o juiz coordenador." A palavra final é a 'cosaisine'. Embora muitos juízes atuem conjuntamente, um deles ficará responsável pela informação. Neste caso, o artigo 83-2 convida-o a coordenar o fluxo de informações.

A palavra chave da reforma - a própria condição de seu sucesso - pode ser a coordenação: nos pólos, tratando de instrução colegiada, e no que diz respeito à cosaisine.

No entanto, a exigência de coordenação ainda pode justificar uma indagação. Na verdade, eu me pergunto se o novo dispositivo - e todo o sistema futuro que seguirá nesta direção - levará a um sistema eficaz. Este requisito não se arrisca a ter um efeito puramente formal, de um único juiz continuar com a realidade de trabalho? E mesmo se houver esta coordenação, seguirá na direção desejada pelo legislador, de um serviço mais eficiente? Além disso, falando de coordenação entre os juízes, não teremos um pouco negligenciados os direitos de defesa e afins? Na mesma linha, também ouvi alguns se perguntarem se a segurança dos pólos não iria mais longe - de qualquer forma irão fisicamente - para contra uma coordenação real, mas desta 
vez entre juízes e advogados. Lembremo-nos de novo a fala do presidente Natali, sobre o famoso e terrível caso do túnel Mont Blanc $^{6}$, onde a instrução foi levada a termo por um único juiz do Tribunal de Bonneville - fora do centro - e constituiu um pleno êxito aos olhos de todos...

De onde então faço novamente a indagação sobre a exigência da coordenação como condição necessária para o sucesso de qualquer trabalho coletivo. Afinal, se há uma coisa que podemos aprender com a sociologia das organizações é que entre a regra e os seus efeitos, muitas vezes há um abismo [7]. Isto significa que os textos não podem nos dizer muito sobre o comportamento real dos jogadores e, portanto, sobre como o sistema funciona. Em outras palavras, eu me pergunto se nós não estamos dando outra vez ao texto legal a ilusão de sua onipotência, acreditando que ele vai levar - como se isso acontecesse mecanicamente - ao comportamento virtuoso, tornando o sistema eficaz porque os indivíduos supostamente devem ser elementos completamente neutros, que só aplicam a lei sem de modo algum interagir com ela. Neste caso, podemos pensar que ainda haverá uma lacuna entre o texto e sua aplicação ao enfatizar a necessidade de coordenação entre as partes interessadas, onde o legislador não utiliza uma definição formal muito restritiva, mas é apostar grande parte do sucesso da reforma sobre o comportamento real dos jogadores que, de alguma forma, ficam por conta própria. Esta é uma questão à qual não podemos, em minha opinião, escapar.

No entanto, vincular os atores - ou seja, para garantir que seu comportamento esteja de acordo com o objetivo pretendido pelo legislador - pode implicar, às vezes, em fazer o sistema jogar em outro aspecto, ou seja, melhorar comunicação entre eles, com base no pressuposto de que a melhoria da comunicação produz uma melhor coordenação.

6 Trata-se do processo decorrente do engavetamento de veículos que provocou um violento incêndio entre 24 e 26 de março de 1999, resultando na morte de 39 pessoas e no fechamento do túnel durante cerca de três anos. (N. do T.) - http:// fr.wikipedia.org/wiki/Incendie du tunnel du Mont-Blanc 


\section{MELHORAR A COMUNICAÇÃO ENTRE OS ATORES}

Comunicação, coordenação: nós fazemos uma observação quase idêntica, o primeiro deve servir o segundo. Neste caso, a melhoria da comunicação (pelo menos desta vez mais entre juízes, do que entre juízes e advogados) se apóia no uso de novas tecnologias. Nos casos criminais, as varas devem permitir um melhor acesso aos arquivos. Em matéria cível, os benefícios iniciam desde a fase de instauração do processo.

Começamos pela matéria criminal e o acesso ao processo penal. Lembro aqui as palavras do juiz Burgaud assinalando aos membros de uma comissão parlamentar que o número de partes e o volume de um caso teriam exigido um oficial de justiça em tempo integral apenas para fotocopiar os documentos e comunicar-se com os advogados em um tempo razoável...

Desmaterializar o procedimento, com digitalização para PDF, pode ser uma ferramenta valiosa a serviço dos direitos da defesa, especialmente em se tratando de processos muito volumosos. Hoje, apenas dois momentos permitem o procedimento eletrônico. Quanto à possibilidade de o advogado consultar o processo diretamente de seu gabinete, ainda é algo de ficção científica - mas talvez por mais dez anos e, como eu entendo, com exceção da seção do Barreau de Cambrai, que é um escritório piloto (como parecem comemorar seus membros) ${ }^{7}$.

Resta concordar sobre o momento quando este procedimento desmaterializado deve ser disponibilizado para o advogado: por força de uma má experiência, a Sra. Leick nos faz um lembrete oportuno de que ao advogado era imperativo poder consultar o processo muito antes da audiência, sob pena de tornar a defesa... ineficaz, na medida em que as provas essenciais são produzidas na fase de instrução.

Resta ainda resolver algumas questões que podem se tornar diabólicas: o risco de roubo ou desvio dos registros. Atualmente,

7 Seção da Ordem dos Advogados de Cambrai. Na França, a comunicação eletrônica dos atos processuais é feita através do sistema e-Barreau, por intermédio da organização profissional. Disponível para consulta em http://www.avocatscambrai.com/ (N. do T.) 
esta é uma clara possibilidade, e com a internet, pode alcançar efeitos muito mais significativos: em um instante, todas as peças de um arquivo podem ser encontradas na web e ser vistas por milhões de pessoas. Vamos lembrar o que aconteceu recentemente na Corte de Cassação sobre o conflito bancário do Sr. Tapie $^{8}$ : a segurança do Palácio não serviu como um firewall (para usar a linguagem informática)!

Uma outra questão pode ser igualmente diabólica. O Sr. Bénichou foi muito enfático ao questionar se a confiança na justiça criminal pode ser delegada a um aparato técnico. Francamente, esta questão (tão fundamental quanto o diabólica) surge de uma só vez nas esferas criminais e civis com o uso de documentos eletrônicos, torna-se muito mais difícil detectar as fraudes. Descobrir a falsidade de uma assinatura eletrônica está longe de ser tão simples como revelar a falsidade de uma assinatura manuscrita...

Deixemos agora a justiça criminal, passando para a justiça civil, onde o processo eletrônico está em fase experimental, com o início do experimento remontando por volta para 2003. Os oradores nos dizem que agora estão enfrentando algumas "armadilhas" de ordem técnica (para usar a palavra escolhida pela presidente Rebboh): duplicidade de redes entre advogados e juízes, exigindo que todos os advogados sejam titulares de um endereço de e-mail, às vezes vários endereços de e-mail para várias redes; necessidade de pesquisas simples, práticas e confiáveis; presença indispensável de engenheiros de computação em número suficiente nos Tribunais, etc.

Abandonando o campo da tecnologia, a presidente Rebboh e Mme. Normand-Bodard nos tem mostrado que a introdução de informatização nas atividades do Estado não serve apenas para adicionar a técnica ao procedimento, ou seja, que esta técnica não é neutra. Primeiro, ela obriga os jogadores

8 Refere-se à indenização milionária concedida a Bernard Tapie contra o banco Credit Lyonnais, em razão da venda da Adidas em 1993 - http://www.lefigaro.fr/ actualite-france/2011/06/09/01016-20110609ARTFIG00441-comprendre-l-affairetapie-credit-lyonnais.php (N. do T.) 
a mudar suas práticas em questões processuais: reduz drasticamente o número de votos em sessão (que teriam ido uma média de 100 para 4, na 4 a Câmara do Tribunal de Grande Instância de Paris), e a não realização das audiências de pré-julgamento (destinadas apenas para resolver problemas prévios ao julgamento, o que requer um excelente conhecimento do caso por parte de todos), etc. Além disso, esta técnica leva a questões jurídicas: nós temos um exemplo muito bom com a constituição de um advogado. Os litigantes são obrigados a constituir um advogado ou advogados, que são cada vez mais numerosos e pertencem a estruturas muito diferentes, passando freqüentemente de uma especialidade para outra, com isso mudando de endereço, até mesmo o eletrônico. Isso levanta uma questão muito prática acerca da identificação e da rastreabilidade dos advogados. Há também a questão - absolutamente crucial - do respeito pela privacidade e confidencialidade. Em suma, faço uma pergunta, junto com a Sra. Normand-Bodard, se o desenvolvimento da técnica não deveria vir acompanhado da criação de alguns requisitos legais para o seu exercício além daque aqueles que existiam antes, o que pode colocar novamente a questão da relação custo-benefício.

Durante o debate sobre estas questões, primeiro me perguntei se não devemos invejar os tribunais administrativos ${ }^{9}$ e, ao mesmo tempo, lamentar - por apenas um momento - o tempo dos advogados nos tribunais administrativos, porque lá os advogados têm a vantagem de ser menos numerosos e menos voláteis..., o que parece facilitar as coisas para aquele órgão. E o presidente Lagourgue disse-nos: em dezembro de 2008, quando os tribunais de segunda instância estiverem todos equipados para que você possa se comunicar eletronicamente com advogados, eles estarão prontos! [8] Na conta do presidente deve estar também, o que não é tão certo pela dimensão dos investimentos envolvidos, verificar se os advogados estão de acordo (ao menos

9 Na França a jurisdição administrativa funciona de forma independente da justiça comum, com órgãos julgadores próprios vinculados ao Conselho de Estado. (N. do T.) 
os milhares que visitam o Palácio), porque no processo eletrônico, pelo artigo 748-2 do novo Código de Processo Civil, está previsto que nada pode ser feito sem o consentimento expresso do destinatário do e-mail, como as várias intimações e notificações por via eletrônica...

Os profissionais estarão assim tão dispostos quando não se tratar mais de comunicar eletronicamente os atos, mas de apresentar as petições em um padrão formalizado?

\section{FORMALIZAR AS PETIÇÕES}

A idéia aqui é impor uma estrutura para as petições das partes, pelo menos quando eles são apresentadas por advogados, por via regulamentar. $\mathrm{O}$ primeiro presidente Chazal de Mauriac disse isso muito explicitamente diante de um auditório silencioso (seria resultado de algum susto repentino?): como parece improvável celebrar um acordo global nesta área, será necessário atuar pela via regulamentar.

Esta idéia faz parte de um movimento que nós conhecemos: o Decreto de 28 de Dezembro de 1998 "introduziu o conceito de intimação 'qualitativa"' [9], o assunto da petição deve conter uma declaração dos motivos de fato e de direito. Nós todos sabemos que o conteúdo do artigo 954 do novo Código de Processo Civil, que tem grande interesse na formulação de reclamações e recursos, como apresentar as provas e as famosas alegações finais que o Sr. Talon nos lembrou, desiludido e com sua ironia cortante, que nunca podem ser a mera compilação de escritos anteriores... lamentando que este movimento de grande escala, destinado a agilizar a prática dos pedidos, acabou tão bem expressa no adágio 'Da mihi factum, tabo tibi jus'!

Tratando mais especialmente do que diz respeito à estruturação das petições, que o presidente Chazal de Mauriac chama de 'suas promessas', várias questões jurídicas ainda surgem e fazem refletir. Exemplo: devemos impor essa formalização só em sede de recurso - e, portanto, exigir apenas de poucos advogados - 
ou impor também a todos os advogados, em primeira instância? Ou ainda se a eventual exigência regulamentar deve ser imposta, ou não, com pena de nulidade ou inadmissibilidade, ou com a possibilidade de correção num prazo determinado?

Em qualquer caso, estas questões revelam o vínculo entre eficácia e formalismo, que pode assim ser formalizado: mais formalismo = mais eficácia. A meu ver, deve-se prestar atenção para a relevância desta equação. Enquanto ouvia os oradores, eu lembrei que - entre outros - o artigo 9o do regulamento do Tribunal de Apelação de Québec em matéria civil, afirma que "o formato do papel é $21,5 \mathrm{~cm} \times 28 \mathrm{~cm}$. Deve ser um papel branco de boa qualidade. O papel pode ter 21,5 centímetros por 35,5 centimetros nos documentos que acompanham o pedido...". Nós poderíamos ir mais longe, mas ainda acho que o trabalho de rotina da papelada suscetível de provocar o aumento do formalismo pode justificar um aumento na tarifa de taxas (devido ao recrutamento de uma série de jovens trabalhadores responsáveis pela tarefa ingrata), enquanto que ele pode ter o efeito simbólico de tornar os litigantes ainda mais desconfiados do sistema judicial que percebem ser decididamente reservado só para o mundo de sacerdotes capazes de saber a fórmula ritual que permite o exercício da acção judicial, mesmo quando os advogados não disponham formalmente o monopólio da representação...

Além disso, todos nós sabemos que a maioria aposta no plano infra-normativo: sempre haverá bons e maus advogados, e aumentar a formalidade da escrita só irá melhorar a qualidade média das petições - o que não é tão ruim. $\mathrm{O}$ advogado com quem estagiei foi um pioneiro do direito econômico, apesar das inúmeras rasuras que pontilhavam suas conclusões, resumiu isso de uma forma viva e marcante: jamais copie esses advogados que apresentam um véu na frente das idéias! Em outras palavras, deixe funcionar a sua imaginação criativa antes de se preocupar com a apresentação formal de suas conclusões. Em suma, a formalização das petições pode nos tranquilizar, fazendo-nos acreditar em uma operação racional, que contém tudo de forma 
clara, mas não vamos nos deixar enganar completamente. Alguns advogados estão na mesma situação dos médicos: alguns nunca farão o diagnóstico correto, mas é melhor que, sem exceção, todos usem sobre as feridas dos pacientes curativos com gaze estéril, ao invés de suja! Em outras palavras, a estruturação das petições é para o procedimento o que a higiene representa para a medicina: é bom, mas não significa tudo. Não nos deixemos enganar por esta estrutura, pois a revolução da audiência está chegando.

\section{REVOLUCIONAR A AUDIÊNCIA}

Gostaria de imaginar um sonho junto com você - a não ser que ele se transforme em algum pesadelo. Feche os olhos e deixemo-nos levar pela imaginação, em 2012 ou 2017. Estamos em um tribunal com uma nova arquitetura - talvez este seja o futuro tribunal de Paris? Ele contém apenas algumas salas de audiência, que são exclusivamente reservadas para os poucos casos criminais que ainda tramitam. A maioria dos outros espaços parecem salas de reuniões, com uma mesa oval grande no centro e nas bordas duas telas (para videoconferência). Como salas dedicadas à mediação e à conciliação, elas são organizadas de maneira um pouco diferente: contêm uma sala central e outras menores, adjacentes, projetadas para permitir que as partes trabalhem juntas de forma discreta nas reuniões.

$O$ advogado que nós acompanhamos deve primeiro defender um caso cível. Antes de sair de seu escritório agora localizado no leste de Paris ${ }^{10}$, verificou o estágio de andamento dos vários processos a que tem acesso eletrônico direto. Uma audiência judicial foi fixada convencionalmente para as 10h15. Nesse instante, ele está sentado (porque ninguém está de pé) diante da famosa mesa oval em frente à parte contrária e ao magistrado, juiz do pré-julgamento, que começa a apresentação oral do seu relatório por escrito. Parece que o presidente

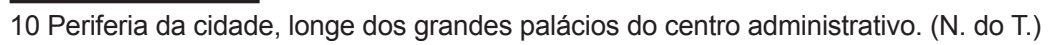


Magendie conseguiu convencer as autoridades a não correr o risco de sobrecarregar o processo legal, e este relatório não precisa ser enviado para as partes antes da audiência. Ele deveria apenas permitir ao juiz pormenorizar de forma objetiva, as alegações das partes ou os elementos de uma questão complexa. Deveria, eu disse, pois como os juristas não leram o venerável Bachelard, tal descrição objetiva seria antes de tudo uma traição... Mas prossigamos: com o desaparecimento da sustentação oral (que vou discutir logo em seguida), o relatório tornou-se essencial para que os advogados possam, pelo menos, verificar se o juiz não tem uma visão muito distorcida do caso. Nenhuma pasta sobre a mesa dos juízes: o tribunal, sentado de forma colegiada (o colegiado aqui é a boa nova), tem todas as peças digitalizadas enviadas eletronicamente pela Secretaria, há algumas semanas. Notamos aqui que os escritos não são muito longos, porque é altamente recomendável não se estender desnecessariamente (copiar e colar foi proibido pelo regulamento). Todos ao redor da mesa já sabem o conteúdo de cada arquivo e simplesmente precisam executa-lo em seu próprio computador portátil, onde estão listadas todas as peças que foram digitalizadas.

Não há mais sustentaçoes orais. Definitivamente acabou o "teatro judicial" (nas palavras do presidente Magendie)! Atendendo ao juiz relator, nosso advogado simplesmente toma a palavra para esclarecer um elemento fático que possa estar faltando no relatório, antes do debate que pode ter lugar entre os auxiliares da justiça e o juiz... Este debate é, naturalmente, de avaliação das provas, mas também sobre os aspectos jurídicos do caso (as chamadas matérias de direito, de que também se falou ao destacar cuidadosamente os argumentos...). Os debates são bastante ásperos, como pode ser observado, graças à - ou por causa da? - Légifrance ${ }^{11}$, os litigantes podem invocar dezenas de decisões inéditas da corte de cassação e dos vários tribunais de

11 Serviço de consulta às decisões dos tribunais franceses - www.legifrance.gouv. fr (N. do T.) 
apelação... Já faz um longo tempo que os advogados se tornaram casuístas, como costumava dizer o velho ditado, tão detestado nos meios acadêmicos, de que uma boa decisão é muito melhor do que um bom princípio! Estes debates também duram mais de duas horas, como o presidente pretendia que todas as questões relevantes fossem objeto de ampla discussão.

Se não fosse a falta da madeira nas paredes, você poderia imaginar estar participando de uma audiência de Arbitragem Internacional nas instalações de uma grande empresa de negócios perto da Place Vendome, a menos que este procedimento apenas nos leve de volta (como propôs a Sra. Moore) a uma audiência perante um juiz-relator do Tribunal de Comércio de Paris dos anos pós-guerra...

Após a audiência, que não terá sido mais curta que as antigas audiências com a antiga sustentação oral (o presidente Henry Bonniot fez questão de dizer), o tribunal irá deliberar sobre o assunto, e o julgamento será enviado diretamente para os litigantes eletronicamente em dois ou três meses (como parece que os juízes e seus funcionários não são menos sobrecarregados do que hoje, apesar do tempo que lhes faz ganhar tal tipo de audiências...). Nosso advogado está aliviado. Tudo correu bem: o equipamento técnico não entrou em pane, o debate seguiu 'plenamente o contraditório' e permitiu descobrir os elementos essenciais do caso. Numa expressão: viva o poder da razão técnico-processual!

A audiência foi um pouco longa, nosso advogado tem pouco tempo para visitar um dos grandes - mas muito poucos - tribunais onde está neste momento a assistir a uma sessão da corte criminal, que começa no início da tarde. E pasme: o público está lá, bem como os juízes e jurados, mas nenhuma testemunha, nenhum perito e nenhum acusado!!! Todos comparecem aos debates, mas apenas em vídeo-conferência. Enquanto os especialistas estão em Saint-Pierre-et-Miquelon (que não deixa de ser um charme, uma vez que foi justamente onde foram as primeiras experiências em vídeo-conferência!), as testemunhas 
estavam aterrorizadas demais para aparecer, e o acusado é demasiado perigoso para ser transferido sem um custo maior (por força de cortes no orçamento)...

A audiência se arrasta e se eterniza: é a sexta vez que o advogado do detento, que decidiu ficar em silêncio, se aproveita do artigo 116-1 do Código de Processo Penal (que parece ter sobrevivido à abolição da lei de 05 de março de 2007) para solicitar ao tribunal que consulte o registro audiovisual dos interrogatórios que aconteceram no gabinete do juiz de instrução. Sistematicamente nega o alcance das declarações recolhidas naquela oportunidade, e deve-se admitir que em duas ocasiões, a consulta ao registro tinha razão de ser... Embora nem tudo tenha sido perfeito para o seu cliente, uma vez que o júri também teve a oportunidade de ouvir a confissão em vídeo do indiciado, o que parece ter tido um efeito desastroso sobre eles, e talvez seja difícil livrar-se dessa impressão, apesar da retração muito posterior do indiciado... $\mathrm{O}$ poder e a perversidade da técnica dizem ao íntimo do defensor, lembrando vagamente os ensinamentos de Jack Goody, que a razão audiovisual prevalece sobre a razão gráfica!

Além disso, o equipamento falhou e foi necessário encontrar um técnico de suporte competente em algum lugar do palácio. As discussões são muito fragmentadas e ninguém consegue se concentrar. Em um aparte, o presidente da sessão (que poderia se chamar Sr. Bernard-Requin) estima que este tribunal por videoconferência (e registros digitais) não permitirá ao júri formar uma convicção íntima - embora a experiência mostre que o uso da tecnologia sirva para aumentar a sua atenção: falta-lhe o barro humano, olhares, sorrisos e emoção! É também esse o parecer do relator do caso (outro Pierre Rancé?), que disse várias vezes ao microfone que as lições do famoso caso Outreau, passados dez anos, definitivamente ainda não foram aprendidas. Não se pode ceder, acrescenta, à miragem da técnica e ao culto de uma pretensa eficácia? Nós queríamos ter um Max Weber, mas temos a herança de Franz Kafka... 


\section{CONCLUSÃO}

Vamos parar por aqui com a apresentação de uma justiça imaginária (civil e criminal) passando a uma performance com menos contraste (o contraste também pode ser invertido). A eficácia do sistema judiciário depende de três fatores: orçamento, estruturas, atores. Os três devem andar juntos: aquilo que falta em uma instituição e não pode funcionar de forma eficaz. Hoje falamos realmente apenas sobre o segundo: as estruturas. Nós sabemos o que está no orçamento: a eleição (estamos em 22 de março) está cheia de promessas, e logo veremos o que elas trazem. Quanto ao terceiro fator (os atores), parece-me que foram invocados na maioria das vezes apenas indiretamente, porque eu suspeito que alguns possam pensar que estes textos querem forçar os atores a mudarem o seu comportamento. É isto que eu chamei anteriormente de ilusão do texto, que pode ficar fora de nossa velha crença (moderna? revolucionária?) na onipotência de uma lei capaz de moldar a realidade; ou que entre o texto e os fatos, entre o texto e a norma de conduta, para repetir, pode haver um abismo. Sobretudo, ao lado desta primeira ilusão, existe outra que consiste na crença num outro poder, numa técnica que produza efeitos de forma unívoca. Ou pode ser ainda que isso esvaziasse o debate sobre os efeitos dos registros eletrônicos de depoimentos: enquanto alguns previram um declínio da credibilidade dos depoimentos para formação da convicção dos juízes, outros apostam em sua manutenção e no reforço da sua capacidade probatória...

Então, vamos olhar para esses famosos atores talvez um pouco mais do que costumamos fazer. Vamos, por vezes, até mesmo rever nossas prioridades. Aprender, por exemplo, a considerar ou reconsiderar a lentidão da justiça em um ângulo mais favorável [10]. Finalmente, pensar numa capacitação séria (inicial e contínuo) que todos nós recebamos. E continuemos, sobretudo, a dialogar incessantemente entre nós. Os Colóquios do Palácio deveriam exercer esta função: garantir que os diferentes atores dialoguem e, portanto, trabalhem juntos para 
melhor se... coordenarem, por exemplo criando fenômenos de rotina, que os economistas nos dizem que melhoram a eficácia das organizações em suas operações diárias.

O segredo da eficácia do sistema judicial está, ao mesmo tempo, em nossas reuniões, maravilhosamente organizadas pela Gazette du Palais, cujo benefício não é quantificável, porque menos relevantes para a técnica do que para a cultura e a experiência, que tem sido mantidas tão bem por Sra. Talon, e de que também falou o célebre juiz Holmes em seu não menos célebre Common Law de 1881, é do que nos fala ainda Pierre Aubenque quando preserva aquela antiga prudência... Precisamos conhecer melhor a nós mesmos, como foi capaz de concluir sabiamente o conselheiro Repiquet. Portanto, é essencial que eu me cale para que nossas discussões possam se repetir: este é o preço para melhorar a eficácia da justiça!

Résumé: Une réflexion sur les entretiens " l'efficacité au service de la justice », organisées par la Gazette du Palais, qui répond aux quatre aspects: (1) de rationnaliser l'organisation de l'institution, (2) d'améliorer la communication entre ses acteurs, (3) de formaliser encore un peu plus les écritures, et (4) de révolutionner l'audience.

Mots-clés: Efficacité. Justice. Organisation. Centralisation Coordination. Communication, écritures, audience, nouvelles technologies.

\section{REFERÊNCIAS}

[1] O que nem sempre acontece, conforme recentemente publicaram Matthieu Boissavy e Thomas Clay, Reconstruire la justice, Odile Jacob, coll. « La 6e République ", Paris, 2006.

[2] Sobre a despolitisação dos debates acerca da instituição judicial desde os anos 1980, ver Antoine Vauchez e Laurent Willemez, La justice face à ses 
réformateurs (1980-2006), PUF, coll. « Droit et justice », Paris, 2007, spéc. p. $11-23$.

[3] Simone Rozès, Une entreprise en activités judiciaires, Revue française d'administration publique 1991, p. 7 .

[4] Cf. sobre esse tema, Roland du Luart, La Lolf dans la justice : independence de l'autorité judiciaire et culture de gestion - Rapport d'information fait au nom de la commission des finances sur la mise en oeuvre de la LOLF dans la justice judiciaire, Sénat, no 478, 13 juillet 2005.

[5] Cf. sobre esse tema, Serge Guinchard et alii, Droit processuel - Droit commun et droit comparé du procès, Dalloz, coll. "Précis ", Paris, 3e éd.,2005, p. 391-496.

[6] Cf. sobre esse tema, Marie-Luce Cavrois, Hubert Dalle, Jean-Paul Jean (dir.), La qualité de la justice, La documentation française, Paris, 2002.

Adde, Jean-Paul Jean, Justice et qualité, Revue de la recherche juridique Droit prospectif 2002, p. 2139-2300.

[7] Cf. para uma visão inicial, Lusin Bagla-Gökalp, Sociologie des organisations, La découverte, coll. « Repères ", Paris, 1998, p. 63-84.

[8] Jean-Louis Lagourgue, La profession d'avoué est prête à relever le défi de la communication électronique!, Les Petites Affiches no 212 du 24 octobre 2006, p. 3-7.

[9] Jean-Claude Magendie et alii, Rapport du groupe de travail sur le thème Célérité et qualité de la justice : La gestion du temps dans le procès, La documentation française, Paris, 2004, p. 47.

[10] Cf. sobre esse assunto, Yves-Marie Morissette, Les lenteurs de la justice sous un angle qui les avantage (1987) 33, Revue de droit de McGill, p. $137-151$. 